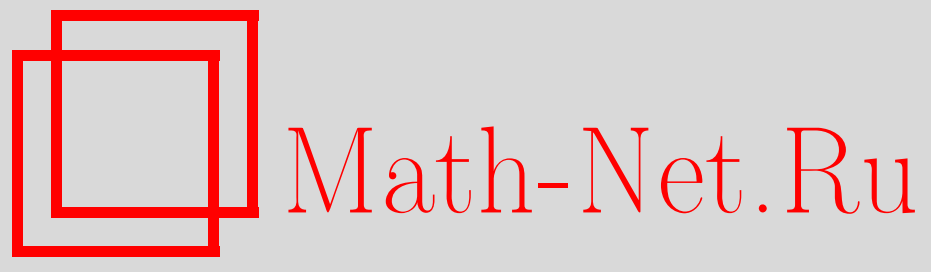

В. П. Маслов, К юбилею Анатолия Ивановича Мальцева, УМH, 2010, том 65, выпуск 5, 204-207

DOI: https://doi.org/10.4213/rm9381

Использование Общероссийского математического портала Math-Net.Ru подразумевает, что вы прочитали и согласны с пользовательским соглашением http://www . mathnet.ru/rus/agreement

Параметры загрузки:

IP : 54.89 .56 .158

26 апреля 2023 г., 16:44:18

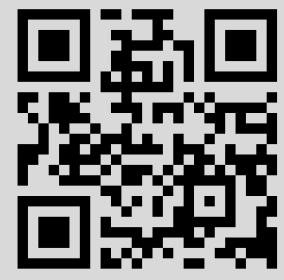




\section{К юбилею Анатолия Ивановича Мальцева}

\section{В. П. Маслов}

Главной наукой - “наукой наук” - вплоть до 18-го века считалась философия и логика как ее раздел. С другой стороны, логика как абстрактное понятие особенно культивировалась среди средневековых схоластов.

Б. Рассел поставил вопрос о выводе математики из логической системы. Между тем математика развивалась как собственным внутренним путем, так и как вспомогательная наука, обслуживающая быстро развивающиеся физику, генетику, технику и другие науки. Казалось, что абстрактная логика далека от насущных практических задач.

Однако в настоящее время становится ясно, что настала пора для науки в целом вернуться к своим основным и коренным проблемам детерминизма и индетерминизма. По существу, физика 20-го века уже поставила эти вопросы и не продвинулась бы, если бы существенно не поменяла идеологию и “веру", обратившись к философии Маха и построив свою логическую цепочку, опираясь на догматы великих физиков. Подчас физики "перескакивали" через логические преграды ввиду необходимости быстрее достичь цели - согласия с новыми экспериментальными открытиями, рождающимися с огромной скоростью. Даже "спортивные" соревнования математиков в решении проблем, поставленных их великими предшественниками, отошли на задний план в свете заделывания тех "дыр", которые обнаруживаются в современной науке.

Уже сегодня настает момент осознания (а дальше осознание будет возрастать по экспоненте) необходимости склеить разорванные логические цепочки без этого невозможно будет двигаться дальше и совершать новые прорывы. Замечу в качестве примера, что недавно венгерские математики из Института математики в Будапеште построили логически непротиворечивую аксиоматику в специальной теории относительности Эйнштейна, позволяющую с логической точки зрения взглянуть на постоянство скорости света.

Л.Д. Ландау и Е.М. Лифшиц, объясняя различие между квантовыми и классическими частицами, пишут в "Квантовой механике": «В классической механике одинаковые частицы (скажем, электроны), несмотря на тождественность их физических свойств, не теряют все же своей "индивидуальности". Именно, можно представить себе частицы, входящие в состав данной физической системы, в некоторый момент времени "перенумерованными" и в дальнейшем следить за движением каждой из них по своей траектории; тогда в любой момент времени частицы можно будет идентифицировать» (Физматлит, М., 
1963, с. 252). Такой возможности “в квантовой механике принципиально не существует" (там же).

Эта концепция связана с тем, что в квантовой механике операторы не коммутируют, а в классической - в пределе при $\hbar \rightarrow 0$ коммутируют.

Колоссальный прорыв в квантовой физике был совершен в середине прошлого века, когда физическая теория блестяще объяснила эксперимент лэмбовского сдвига. Это была зарождающаяся квантовая электродинамика и квантовая теория поля. Эта теория была в решающей степени индуцирована работами Фейнмана. Проследим за логикой Фейнмана, которая особенно ярко отражена в его докторской диссертации 1942 г. Исходным моментом рассуждения Фейнмана было замечательное наблюдение, которое сегодня называется фейнмановским операторным исчислением. Фейнман заметил, что если определить порядок действия некоммутирующих матриц $A$ и $B$ (т. е. $A$ всегда действует первым, а $B$ - вторым) и пронумеровать их, то формула Тейлора для разложения в ряд Тейлора остается верной для экспоненты

$$
e^{\stackrel{1}{A}+\stackrel{2}{B}}=\sum \frac{(\stackrel{1}{A}+\stackrel{2}{B})^{n}}{n !},
$$

что достаточно сложно проверить, так как

$$
e^{{ }^{A}+\stackrel{2}{B}^{2}}=e^{B} e^{A}=\sum_{n=0}^{\infty} \frac{\sum C_{n}^{k} B^{k} A^{n-k}}{n !} .
$$

Он применил эту логику нумерации некоммутирующих операторов даже для случая операторов, зависящих от непрерывного параметра, указывающего на порядок действия оператора. Отсюда возникли знаменитые фейнмановские диаграммы и фейнмановский континуальный интеграл.

Покажем логическую противоречивость (точнее, ограниченность) исходной посылки Фейнмана.

Пусть $A$ и $B$ - генераторы алгебры Гейзенберга. Тогда

$$
(\stackrel{3}{A}-(A+\stackrel{4}{A} B)) f(\stackrel{1}{A}, \stackrel{2}{B}, \stackrel{3}{A}) \neq 0
$$

при $\varepsilon=0$, если $^{1}$

$$
f(x, y, z)=\frac{e^{-i(x-z) y}-1}{x-z},
$$

что является контрпримером к общей концепции нумерации Фейнмана.

Другой пример касается логики другого великого физика Гиббса и также относится к эквациональной логике и непрерывной теории вероятностей.

Предельное распределение частиц классической механики $F(p, q)(p$ - импульс, $q$ - координата), когда время $t$ стремится к $\infty$, должно естественно удовлетворять стационарному уравнению Лиувилля $\{H(p, q), F(p, q)\}=0$, где $H(p, q)$ - гамильтониан. Отсюда следует равенство $F(p, q)=\Phi(H(p, q))$. Если $H(p, q)=H_{1}(p, q)+H_{2}(p, q)$, причем системы, отвечающие $H_{1}(p, q)$ и $H_{2}(p, q)$, не

\footnotetext{
${ }^{1}$ В. П. Маслов, Операторные методы, Наука, М., 1973.
} 
взаимодействуют, т. е. являются независимыми, то распределения должны перемножатъся: $\Phi\left\{H_{1}(p, q)+H_{2}(p, q)\right\}=\Phi\left(H_{1}(p, q)\right) \Phi\left(H_{2}(p, q)\right)$, а это возможно только в случае

$$
\Phi(H)=e^{-c H}, \quad c=\text { const. }
$$

Противоречие нашел сам Гиббс - это так называемый знаменитый парадокс Гиббса.

С этим парадоксом пытались справиться А. Пуанкаре, Г. Лоренц, Я. Вандер-Ваальс, В. Нернст, М. Планк, Э. Ферми, А. Эйнштейн, Дж. фон Нейман, Э. Шрёдингер, И. Е. Тамм, П. В. Бриджмен, Л. Бриллюэн, А. Ланде и другие знаменитые ученые.

Как мы видим, оба приведенных примера очень похожи друг на друга. Когда математики предложили Больцману, по существу, пронумеровать частицы газа, а затем применить теорему о возвращаемости Пуанкаре или повернуть их вспять, он воскликнул: "Пойдите, поверните их!"

Чтобы “заделать все эти дыры”, необходим переход к новой философии, отличной от философии Маха.

Ученым, заложившим основы новой современной научной идеологии, - идеологии, без которой невозможно обойтись, к которой неизбежно обратится и физика, и вычислительная техника, и генетика - является Анатолий Иванович Мальцев.

Мне уже встречались работы в ведущих физических журналах, в заголовках которых стоит термин "алгебры Каца-Муди-Мальцева". Эквациональное программирование, эквациональная логика невозможны без условий Мальцева. "Условия Мальцева" в качестве названия рубрики уже вошли в международный рубрикатор "Subject Classification", и это означает, что число работ на эту тему очень велико. "Кольца и алгебры Мальцева" также выделены отдельной рубрикой в этом классификаторе ${ }^{2}$. Можно легко убедиться, обратившись к международному реферативному журналу, что под этой рубрикой появляется все больше и больше работ.

В книге, посвященной памяти великого А.Н. Колмогорова, перечисляются термины теории вероятностей, в которых закрепилось его имя ${ }^{3}$. Перечислим и мы широко известные термины с именем Анатолия Ивановича Мальцева:

Условие Мальиева,

Алгебра Малъцева,

Кольцо Мальиева,

Oператор Мальиева,

Теорема Wedderburn'a-Мальцева,

Лемма Мальиева,

Категории Мальцева,

2Эти две рубрики имеют номера: 08 B05 (Equational logic, Mal'cev (Mal'tsev) conditions) и $17 \mathrm{D} 10$ (Mal'cev (Mal'tsev) rings and algebras).

${ }^{3}$ Отмечу, что в современный рубрикатор "Subject Classification" ни один из этих терминов в области теории вероятностей не вошел, однако термин из области логики "колмогоровская сложность" вошел. Это говорит о том, что на данном этапе научно-технического прогресса теория вероятностей сдает свои позиции в пользу логики. Сам Колмогоров, исправивший противоречие в дискретном подходе фон Мизеса, признал в своей работе по теории сложности логическое несовершенство непрерывного подхода к теории вероятностей. 
Топология Мальцева,

Соотношение Мальцева,

Структура Мальцева,

Базис Мальцева,

Декомпозичия Мальцева,

Теорема Мальцева.

Можно только сожалеть, что такой великий ученый преподавал не в ведущих вузах страны, а в городе Иваново. Когда А. И. Мальцев переехал в Новосибирск, там под его руководством возникла замечательная школа (его учениками были Ю. Л. Ершов, С. С. Гончаров и другие известные ученые; упомяну, кстати, важное достижение одного из них - алгебры Ершова).

Судьба ученого распорядилась крайне несправедливо, не дав ему при жизни достаточно широкой аудитории. И из жизни он ушел так рано.

Разумеется, время расставит всех по своим местам и уже сейчас расставляет. Уже сейчас ясно, что математическая логика в современной науке есть самая востребованная область, и ее величайшим основателем в современной концепции является Анатолий Иванович Мальцев. 